\title{
Malhas da Hospitalidade ${ }^{1}$
}

\author{
Fabrics of Hospitality
}

Faustino Teixeira*

\begin{abstract}
Resumo
O século XXI depara-se com um dos desafios mais candentes de todos os tempos. Como reagir aos impasses que acompanham o ciclo do Antropoceno, com todas as suas consequências nefastas e necrófilas? Duas possibilidades se apresentam: a conformidade diante da situação ou a reação crítica e profética, com base na esperança da hospitalidade e do diálogo. Num tempo marcado pelo crescimento dos etnocentrismos, xenofobismos e fundamentalismos, a provocação do diálogo e da acolhida ao outro urge com um significado único. Diálogo e Hospitalidade são expressões que se interagem e complementam. Diante do quadro atual, marcado pelo apelo da interligação, há que ampliar as malhas dessa acolhida, envolvendo não apenas os humanos, mas abrindo o leque para a dimensão mais ampla de toda a criação. $O$ ser humano está relacionado, está vinculado na rede maior que tece o universo. Habitar a Terra ganha, assim, um significado novo, de inserção do humano no mundo da vida.
\end{abstract}

Palavras-Chave: Hospitalidade; Diálogo; Cuidado; Espiritualidade; Interligação

\begin{abstract}
The 21st century faces one of the most singular challenges of all times. How to react to the obstacles that follow the cycle of the Anthropocene, with all its disastrous and putrid consequences? There are two possible ways: acceptance of the situation or the critical and prophetic reaction, that lies on the ground of hospitality and dialogue. When ethnocentrism, xenophobia and fundamentalism grow, dialogue and acceptance of the other urge with a special meaning. Dialogue and Hospitality are expressions that interact and complement each other. Facing the current situation that is asking for interconnection, we must broaden the fabrics of this reception, including not only human beings, but opening the scope to a wider dimension of all creation. Humankind is related, is linked to a larger web that weaves the universe. Inhabiting the Earth gains a new meaning, to be part of life itself.
\end{abstract}

Key words: Hospitality; Dialogue; Care; Spirituality; Interconnection

\footnotetext{
Artigo recebido em 20 de fevereiro de 2017 e aprovado em 21 de março de 2017.

${ }^{1}$ Este artigo é fruto do estágio sênior que fiz na Itália (Veneza), com financiamento da CAPES, a quem agradecemos, realizado de dezembro de 2015 a fevereiro de 2016.

* Doutorado e pós-doutor em Teologia pela Pontifícia Universidade Gregoriana (1985 e 1998 - com supervisão de Jacques Dupuis). Atualmente é professor titular da Universidade Federal de Juiz de Fora. País de Origem: Brasil. E-mail: flcteixeira@icloud.com.
}

Horizonte, Belo Horizonte, v. 15, n. 45, p. 18-39, jan./mar. 2017 - ISSN 2175-5841 


\section{Introdução}

O diálogo e a hospitalidade traduzem o desafio mais essencial nesse século XXI. Deixar-se hospedar pelo outro, com todos os desdobramentos aí envolvidos, é o caminho que se abre nesse tempo sombrio das afirmações identitárias e dos fundamentalismos nefastos. Para tanto, firma-se o passo do diálogo. Dizia com vigor o teólogo suíço Hans Küng, no final do século passado, que a paz no mundo implicava a paz entre as religiões, e que a paz entre as religiões era pressuposto para o diálogo entre as religiões (KÜNG, 1992, p. 7). Esse projeto de calor ecumênico veio assumido com empenho pelo papa Francisco. Em sua visita ao Brasil, em julho de 2013, assumiu seu papel protagônico nesse campo. Em discurso no Teatro Municipal do Rio de Janeiro, traduziu a convocação que o move: diálogo, diálogo, diálogo. A nobre palavra, repetida por três vezes, como forma de expressar o único caminho que se abre para o crescimento de uma sociedade e das pessoas. Estava lançado o seu projeto em favor de uma "cultura do encontro" (PAPA FRANCISCO, 2013, p. 82-83). Mais recentemente, em entrevista concedida ao jornal El País, volta a insistir no diálogo, num momento histórico sombrio, quando lideranças conservadoras vão assumindo a rédea de muitos países. Sublinha que em tempos de crise o discernimento tende a falhar. Busca-se em várias partes um "salvador" que resgate a identidade, protegendo as fronteiras com muros e arames farpados e realçando a diferença com os outros povos. O medo do terrorismo e dos atentados acaba provocando uma reação contra os estrangeiros, os diferentes, e suscitando o controle rígido das fronteiras. Francisco reconhece o direito desse controle, mas reage contra sua radicalização, insistindo no caminho do diálogo: "Nenhum país tem o direito de privar seus cidadãos do diálogo com os vizinhos" (PAPA FRANCISCO, 2017)

$\mathrm{Na}$ mesma linha dialogal, o posicionamento do estudioso palestino, Edward Said, na sua contundente crítica à visão de Samuel Huntington, autor de polêmico artigo sobre o "choque das civilizações", publicado no verão de 1993. Foi a visão que predominou em determinados segmentos do mundo, indicando que as 
civilizações são homogêneas e monolíticas. Para Said, é um posicionamento que acaba mobilizando as paixões nacionalistas e seus frutos mortíferos. Ideólogos como Huntington acabam transformando as "civilizações" e "identidades" em algo que não são, ou seja,

entidades fechadas, lacradas, que foram expurgadas da miríade de correntes e contracorrentes que animam a história humana, e que ao longo dos séculos tornaram possível para essa história incluir não apenas guerras de religião e conquista imperial, mas também ser uma história de trocas, fertilização mútua e compartilhamento (SAID, 2003a, p. 43).

Quando se acentua o "choque de civilizações" ou culturas, apaga-se o traço silencioso, mas muitas vezes efetivo, do intercâmbio e diálogo que anima os povos em seu processo de afirmação. Como apontou Said, “as culturas são em geral mais naturalmente elas mesmas quando entram em parceria com outra” (SAID, 2003b, p. 330). Esse empreendimento cooperativo se dá em vários setores, como na música e nas artes em geral. Trata-se de um espírito essencial, envolvendo a cooperação e o intercâmbio. É também um compromisso existencial, como expresso por buscadores singulares, entre os quais Louis Massignon e tantos outros, que fizeram de sua vida uma peregrinação no terreno da alteridade. Fora desse caminho não há futuro promissor, mas apenas o bater estridente e superficial da defesa cega da cultura das particularidades contra todas as demais.

A acolhida da diversidade e do pluralismo não é algo simples ou natural, mas envolve um esforço e uma dedicação particulares. Abraçar o pluralismo como um valor é um dom presente entre alguns "virtuosos”, pois a maioria das pessoas vive uma resistência surda ou ativa contra tal desafio, pois o mundo plural provoca nelas insegurança e temor. Nada mais complexo do que um "mundo confuso e cheio de possibilidades de interpretação", um mundo que abre diferentes possibilidades de vida (BERGER; LUCKMANN, 2004, p. 54).

A hospitalidade envolve uma gama de intrincadas relações, e diz respeito à acolhida do outro e da aceitação da diferença. É um tema chave na abordagem 
relacional entre os seres humanos. $\mathrm{O}$ objetivo proposto neste artigo é reconhecer a força desta dinâmica mas indicar os novos desafios que envolvem esta temática, ampliando as cordas da hospitalidade, de modo a incluir o traço da interligação com toda a dinâmica da criação. Daí se falar em novas malhas da hospitalidade.

\section{Hospitalidade e Diálogo}

Há uma relação mútua entre hospitalidade e diálogo. O diálogo requer hospitalidade. O diálogo está para além de uma mera coexistência, envolve o reconhecimento e o respeito pelas diferenças, bem como o lugar das convicções. Nas relações que se estabelecem entre os interlocutores ocorre a busca de "um conhecimento mútuo e um recíproco enriquecimento” (PCDI, 1991, p. 11).

O diálogo verdadeiro envolve uma acolhida do pluralismo religioso ${ }^{2}$. Para tanto, busca-se superar a ideia limitada de que o pluralismo religioso é um fator negativo ou passageiro, fruto de uma compreensão equivocada da realidade ou de uma percepção maculada do religioso. É uma proposta que supera a visão tradicional e recorrente de que a religião particular é a única verdadeira e que as outras tradições não passam de expressões limitadas do divino ou no máximo antecipações ou marcos de espera de uma verdade que não está a seu alcance. Semelhante perspectiva acaba por entender o pluralismo religioso como um dado de fato, contingente ou passageiro, a ser "aturado" ou dizimado pelo trabalho missionário. Em sua Carta a um religioso Simone Weil expressou com clareza sua dificuldade em acatar tal perspectiva:

A religião católica contém explicitamente verdades que outras religiões contêm implicitamente. Mas, reciprocamente, outras religiões contêm explicitamente verdades que só são implícitas no cristianismo. O mais instruído cristão ainda pode aprender muito sobre as coisas divinas em outras tradições religiosas, embora a luz interior também possa fazer com que ele perceba tudo através da sua. Contudo, se essas outras tradições desaparecessem da superfície da Terra, seria uma perda irreparável. Os missionários já fizeram desaparecer demasiadas (WEIL, 2016, p. 21-22).

2 É extensa a bibliografia sobre o diálogo inter-religioso e o pluralismo religioso. Ver a respeito: TEIXEIRA, 2014. 
Para Simone Weil, o sentimento de respeito e acolhida das religiões era uma questão de honestidade e honradez. Sua abertura à beleza do mundo e à totalidade da criação envolvia a receptividade interreligiosa. Já anunciava, assim, em meados de 1950, um tema que ganharia presença na teologia posteriormente, com a abertura ao pluralismo de princípio ou de direito. Trata-se de um pluralismo acolhido por Deus em seu mistério, enquanto expressão mesmo de sua vontade, que "necessita da diversidade das culturas e das religiões para melhor manifestar as riquezas da Verdade última” (GEFFRÉ, 2006, p. 137). Não há como apagar o mistério que habita na pluralidade dos caminhos que levam a Deus (GEFFRÉ, 2005, p. 21). Há algo de irredutível e irrevogável nas religiões, que não pode ser sumariamente reduzido a um implícito cristão.

É verdade que as religiões como tais são envolvidas também por situações de ambiguidade e limitação. Há que manter sempre aceso o discernimento, reconhecendo que nem tudo que brilha nas religiões é fruto da graça (PCDI, 1991, p. 23). Mas o caminho que se abre não é o de firmar simplesmente as diferenças, mas o de indicar a dignidade das singularidades e originalidades e não simplesmente reiterar uma assimetria. É desconhecer e macular a extraordinária diversidade das tradições religiosas querer delas conservar como valor simplesmente o seu potencial de abrir-se positivamente àquilo que ignoram (DUQUOC, 2008, p. 168). Em sua exortação apostólica, Evangelii Gaudium, sobre o anúncio do evangelho no mundo atual, o papa Francisco sublinhou com ênfase que "a diversidade é bela", acolhendo assim esse campo novo e audaz de abertura ao pluralismo de princípio (PAPA FRANCISCO, 2013b, p. 130).

\section{Disposições para o diálogo}

A acolhida inter-religiosa requer do sujeito um leque de disposições que são essenciais. Para que ocorra um diálogo autêntico é necessário, em primeiro lugar, alimentar a vida com uma atitude de busca essencial e profunda. Partir sempre animado pela convicção de que se está trilhando um caminho "em solo sagrado" 
(PANIKKAR, 1993, p. 1149). O outro é portador de um "patrimônio religioso" que não pode ser relevado ou minimizado. A busca de um contato estreito e desarmado com o outro é também um requisito essencial:

Uma justa avaliação das outras tradições religiosas supõe normalmente um estreito contato com elas [...]. Devemo-nos aproximar destas tradições com grande sensibilidade, porque encerram valores espirituais e humanos. Exigem respeito da nossa parte visto que, no curso dos séculos, deram testemunho dos esforços feitos para encontrar as respostas 'aos mais árduos problemas da condição humana '(NA 1) e expressão à experiência religiosa e às expectativas de milhões de adeptos seus, e continuam a fazê-lo hoje (PCDI, 1991, p. 13).

Há que partir animado por esse "espírito do diálogo", que envolve uma atitude primeira de respeito e amizade. E também o reconhecimento sincero do "valor da convicção religiosa" do outro, fundada numa experiência autêntica de revelação (TILLICH, 1968, p. 133). Como mostrou Christian Sevenaer, um dos mais singulares buscadores jesuítas, com longa atuação dialogal no Egito com os muçulmanos, o respeito ao outro é condição primeira, ou seja, o respeito pelas pessoas, por suas convicções de fé e suas tradições religiosas, reconhecendo que ali vivenciam o que há de mais precioso (SEVENAER, 2006, p. 131). Esse clima espiritual deve circundar todos os passos do processo de abertura, com a disposição atenta para colocar-se sempre em discussão. O diálogo não pode ser entendido como alavanca para outra coisa; não pode ser captado como passo para a evangelização. Na verdade, o diálogo “tem seu próprio valor”, é auto-finalizado, guarda um valor intrínseco. A razão do diálogo é o diálogo e como horizonte visado, "uma conversão mais profunda de todos para Deus" (PCDI, 1991, p. 28). E isto sucede em todas as formas de diálogo, seja no diálogo da vida, das obras, dos intercâmbios teológicos e da experiência religiosa.

Ao lado da busca essencial, o diálogo requer igualmente uma atitude de humildade. A abertura ao outro exige esse desprendimento, essa consciência da contingência e da vulnerabilidade. Como indica Panikkar, "nenhum indivíduo, nenhum grupo humano, nem mesmo toda a humanidade vivente em dado 
momento da história pode encarnar a medida absoluta da verdade" (PANIKKAR, 2013, p. 149). Nada mais letal para o diálogo do que o sentimento de superioridade, de hybris arrogante ou de desprezo ainda que escamoteado. O diálogo requer esse esvaziamento de si, essa kenosis, para poder deixar valer o outro, esse deslocamento essencial, essa abertura de coração.

Há também outra disposição importante, que envolve a simpatia e a atenção para com o outro. Há que se lançar ao outro, expor-se ao seu enigma e mistério com a cuidadosa aplicação do espírito. Estar atento e vigilante para adentrar-se nas suas fronteiras, sintonizar-se com a sua vida. Tem um toque de perigo e de risco nessa aventura, como bem descrito por Thomas Merton: "Quando as cordas são largadas e o barco já não está mais preso à terra, mas avança para o mar sem amarras, sem restrições! Não o mar da paixão, pelo contrário, o mar da pureza e do amor sem preocupações" (HART; MONTALDO, 2001, p. 270). Simone Weil falava da "virtude milagrosa da simpatia”, caminho essencial para adentrar-se no mundo interior do outro; e também da atenção, como "a forma mais rara e mais pura da generosidade" (WEIL; BOUSQUET, 1994, p. 13; WEIL, 2000, p. 113). Virtudes que são essenciais para o conhecimento do outro a partir de dentro, quebrando as hierarquizações problemáticas. Ela dizia, com acerto, que "aquele que conhece o segredo dos corações é o único que conhece também o segredo das diferentes formas de fé" (WEIL, 2000, p. 113). A atenção é porta de entrada para a hospitalidade.

\section{0 impacto da alteridade}

A alteridade vem resguardada por um patrimônio de mistério que se revela a cada momento, deixando a todo tempo uma virtualidade a ser captada. Ela sempre desconcerta e seduz. Traduz primeiramente o mistério da maravilha, que é fascínio e admiração. É quando a alteridade apresenta-se de maneira substantiva e se dá o impacto com o outro, com a sua inusitada e improgramável presença. É essa admiração que faculta o estupor e aciona uma provocação inédita de desarme e 
abertura. Em sua preleção sobre a metafísica, em 1929, Martin Heidegger sinaliza esse encontro com a "estranheza do ente". A admiração acontece justamente no momento em que essa estranheza acossa o sujeito, levando à indagação e ao porquê (HEIDEGGER, 1969, p. 43).

A presença do outro suscita não apenas maravilha, mas também agonia, na medida em que sua presença provoca desconcerto e um desvio do caminho seguro até então trilhado (FORTE, 1999, p. 61). É a outra face da dinâmica da alteridade, que convoca à experiência do limite e da fronteira, de auto-exposição ao mundo do outro. Os caminhos da hospitalidade envolvem também esse processo de agonia e estranhamento. Isso foi apontado com acerto pelo estudioso Alain Montandon, em precioso prefácio ao livro por ele organizado (MONTANDON, 2011). Para tratar do tema, parte de uma indagação feita por Ulisses na Odisseia, quando percorria os mares em aventuras que eram testes de hospitalidade. Quando chegava a uma nova praia, defrontava-se sempre com uma singular pergunta: "Vou encontrar brutos, selvagens sem justiça, ou homens hospitaleiros, tementes aos deuses?” (HOMERO, 2011, XIII, vv. 200-2002). A hospitalidade era, assim, um sinal de civilização e humanidade. Com base no clássico ensaio de Marcel Mauss sobre a dádiva, Montandon indica que a hospitalidade não se reduz simplesmente ao oferecimento de um abrigo ou repasto, mas revela-se como um "fenômeno social total”. O que se partilha "não são apenas bens de consumo, mas cortesias, banquetes, ritos, danças, festas" (MONTANDON, 2011, p. 32).

A hospitalidade tem início na soleira da porta, quando se dá o "embate” com o rosto de um desconhecido, de um estranho ou estrangeiro. Ali se coloca a delicada questão do "limite entre dois mundos", o de dentro e o de fora. Trata-se “da linha de demarcação de uma intrusão, pois a hospitalidade é intrusiva, ela comporta, querendo ou não, uma face de violência, de ruptura, de transgressão, até mesmo de hostilidade" (MONTANDON, 2011, p. 32). É o que Derrida chamou de "hostipitalidade", na medida em que essa dinâmica de encontro/embate sinaliza uma fronteira e mesmo uma ameaça. A hospitalidade demarca um limiar, ou seja, 
uma linha que envolve transgressão, intrusão. Penetrar no domínio do outro

é um problema tanto de proxêmica ${ }^{3}$ quanto de propriedade. 'Território é terra mais terror '. Eis a questão do próprio, daquilo que constitui minha identidade no pertencimento a um território, a um espaço em que o outro é visto, de uma maneira ou de outra, como um intruso (MONTANDON, 2016, p. 35).

O território do outro vem resguardado por uma "sensibilidade escrupulosa”. Há que bater devagar, com cuidado, na porta do outro. Entrar no novo circuito requer cautela, delicadeza e atenção. Há que manter despojamento e renunciar a se impor. O gesto da hospitalidade pressupõe romper resíduos de hostilidade sempre implicados nos atos que envolvem o encontro4. Isto não significa romper a distância, que permanece vigente: "O paradoxo do gesto hospitaleiro é o de dever oferecer preservando, de manter a distância instaurando uma presença" (MONTANDON, 2011, p. 35). Não se trata apenas de uma "acolhida integradora”, mas também de radical respeito à alteridade, que é irredutível e irrevogável. Na prática da hospitalidade ocorre a transformação que implica uma dádiva de si.

Como condição essencial da hospitalidade está o diálogo, o passo do eu ao nós, do exercício da amizade, que envolve a acolhida do outro na esfera da intimidade. Há no diálogo um singular exercício de ultrapassar fronteiras, de avançar para além dos limites de nossa finitude e contingência. O diálogo deixa sempre uma "marca” que é reveladora de um horizonte inaudito:

O que perfaz um verdadeiro diálogo não é termos experimentado algo de novo, mas termos encontrado no outro algo que ainda não havíamos encontrado em nossa própria experiência de mundo (...). O diálogo possui uma força transformadora. Onde um diálogo teve êxito ficou algo para nós e em nós que nos transformou. O diálogo possui, assim, uma grande proximidade com a amizade (GADAMER, 2002, p. 247).

\footnotetext{
${ }^{3}$ Trata-se de um termo cunhado pelo antropólogo inglês Edward T. Hall para descrever o espaço pessoal de indivíduos num meio social. Diz respeito às distâncias físicas que as pessoas estabelecem espontaneamente entre si no convívio social, bem como das variações que podem ocorrer dadas as mudanças sociais e culturais.

${ }^{4}$ Curioso verificar que na derivação etimológica de hostes estão tanto o hóspede como o inimigo (hospes/hostis). Nesse sentido, "da hospitalidade à hostilidade há apenas um passo". O desafio dialogal é o de propiciar "relações de amizade no interior de uma relação suscetível de conter os germes de relações adversárias": HAROCHE-BOUZINAC, 2011, p. 1259.
} 
Não há caminho promissor senão através do diálogo, mesmo reconhecendo as dificuldades e tensões que marcam sua realização. É sempre "um tesouro precioso, uma zona de aventura, espanto e inquietação” (LUCCHESI, 2014). É uma "zona de passagem", uma "cartografia inacabada", onde os interlocutores são convidados, mantendo sua identidade, a refletirem sob nova luz. Deslocados de seu eixo são direcionados a um novo ponto de luz e a um gesto solidário. No centro do diálogo está a acolhida: "na beleza do rosto que contemplo, no olhar do outro que me indaga e me convida a mover os lábios” (LUCCHESI, 2014). O diálogo é expressão viva da nobre virtude da hospitalidade. Ele requer a abertura das portas, do respiro aberto, do espaço luminoso. É condição essencial para uma cultura da paz.

O encontro com o outro não pode reduzir-se a um "rebuliço sonoro", mas deve envolver os corações e mentes num movimento de amizade e busca de compreensão mútua. Não são individualidades estanques e impenetráveis que se encontram, mas dois mundos que se envolvem, ainda que resguardando um mistério que é intransponível5. É a própria individualidade que é convocada a expandir-se e apropriar-se de novas possibilidades. Não é algo simples, pois envolve um embate interior, de remoção das entranhas para deixar-se hospedar pelo diferente. Desse encontro novidadeiro surge sempre algo de novo, uma marca diferencial.

Nesse imprescindível processo dialogal, os interlocutores entram com a alegria de suas convicções religiosas. Não se exige a abdicação das identidades para que esse processo se realize com êxito. Ao contrário, é a própria autenticidade e sinceridade do diálogo que convoca os parceiros a embarcarem nessa travessia mantendo viva a integralidade de sua própria fé (TILLARD, 2000, p. 34; PCDI, 1991, p. 32-33). Para exemplificar, o testemunho vivo do jesuíta e padre do deserto, Paolo dall’ Oglio, quando provocado sobre a sua experiência de diálogo com os

\footnotetext{
${ }^{5}$ Rainer Maria Rilke abordou com precisão esse mistério/enigma que envolve o exercício do amor: "O amor de duas criaturas humanas talvez seja a tarefa mais difícil que nos foi imposta, a maior e última prova, a obra para a qual todas as outras são apenas uma preparação". Não há como apagar a "solidão" que permeia esse encontro. Há que saber lidar com ela: RILKE, R.M. 2013a, p. 54-55.
} 
muçulmanos no deserto de Mar Musa (Síria). Indagado sobre seu itinerário, respondeu com tranquilidade: “Abrimo-nos profundamente à religião muçulmana e à sua civilização, em virtude da tranquilidade de nossa fé em Cristo, e não por uma dúvida a seu respeito" (LUCCHESI, 2000, p. 57). O diálogo pressupõe pertença e domiciliação, amor à própria identidade, mas uma identidade sempre em construção, aberta ao sussurro contínuo do plural. Uma das finalidades do diálogo é "o de poder viver a diferença de modo positivo, no respeito, na aceitação do outro assim como é, sem violência nem desprezo e sem dever esconder a diferença” (SEVENAER, 2006, p. 116).

\section{Novas malhas da hospitalidade}

As novas reflexões em torno da espiritualidade da criação indicam um caminho novo para o tema da hospitalidade. Não há como pensar o ser humano desligado de sua relação com o campo mais amplo. A antropologia requer uma cosmologia. Como mostrou Matthew Fox, “a história humana não pode ser separada da história planetária, da história galáxica, e de toda a história da criação que continua a desenvolver-se" (FOX, 2016, p. 31). O ser humano se define por sua relação com toda a criação, formando um parentesco que abre frestas singulares para a dinâmica de sua inserção no mundo. Em sua encíclica sobre o cuidado da casa comum, Laudato si, o papa Francisco realça essa sintonia: "Esquecemo-nos de que nós mesmos somos terra (cf. Gn 2,7). O nosso corpo é constituído pelos elementos do planeta; o seu ar permite-nos respirar, e a sua água vivifica-nos e restaura-nos" (FRANCISCO, 2015, p. 3).

Pensar a hospitalidade, e também o diálogo, dentro deste novo quadro complexivo envolve uma percepção nítida do que significa habitar a Terra. Entender agora o ser humano em sua relacionalidade mais radical, como um ser que se move e se articula, e se deixa transformar. Tudo provoca um novo olhar: "Estar atento significa estar vivo para o mundo" (INGOLD, 2015, p. 13). E estar vivo é poder captar o "nexo singular de crescimento criativo" do humano inserido 
no âmbito dos relacionamentos. A expressão "malha" é a que melhor traduz a nova situação. Considerando que a malha implica a textura de fios entrelaçados, esta percepção aplica-se à vida, que igualmente perfaz uma trilha, ou fios que compõem o mundo habitado. A vida é pontuada por linhas entrelaçadas que formam uma malha.

Exercer a condição de ser humano é poder habitar a Terra, reinserindo-se na continuidade do mundo da vida. A textura do mundo envolve este entrelaçamento. Não se trata apenas de ocupar o mundo, mas de habitá-lo com sentido. E o mundo deixa de ser visto como um substrato inerte onde os seres vivos se locomovem, mas como um mundo em movimento:

Onde quer que haja vida, há movimento. Nem todo movimento, no entanto, indica vida. O movimento da vida é especificamente o de tornarse, em vez do de ser, da incipiência da renovação ao longo de um caminho, em vez do da extensividade do deslocamento no espaço (...). O sol está vivo devido à maneira como se move através do firmamento, mas também o estão as árvores, devido aos modos peculiares de seus ramos se moverem e suas folhas tremularem ao vento, e devido aos sons que emitem ao fazê-lo (INGOLD, 2015, p. 122).

Essa percepção de um mundo em movimento, de um mundo "encantado", vem recuperar cosmologias antigas e primordiais, com os seus dons e inquietudes. Curioso verificar que o recurso a tais cosmologias vem sendo apontado por estudiosos da antropologia como um caminho importante para um novo modo de inserção na história (LATOUR, 2012, p. 452)6. A Carta da Terra pontua a importância do reconhecimento e preservação dos conhecimentos tradicionais, bem como da sabedoria espiritual presente entre os povos das diversas culturas, como condição essencial para a proteção ambiental e o bem-estar humano (BOFF, 2002, p. 154).

Em sugestiva abordagem, Tim Ingold fala da singularidade da ontologia anímica, quebrando a imagem de que o mundo inanimado seja simplesmente uma

${ }^{6}$ Veja também Eduardo Viveiros de Castro, no prefácio ao livro de KOPENAWA, D.; ALBERT, B, 2015, p. 35. 
superfície a ser ocupada. Na verdade, segundo tal ontologia, os seres vivos "fazem o seu caminho através de um mundo nascente, em vez de pela sua superfície préformada” (INGOLD, 2015, p. 123). O desafio maior está na capacidade de VER o mundo nesta perspectiva de vitalização, abrindo novas pontes para o pensamento. Isto significa reconectar o pensamento com a vida. A retomada de antigas cosmologias, entre as quais o animismo dos povos originários, suscita na prática uma "reanimação" da própria "tradição 'ocidental de pensamento" (INGOLD, 2015, p. 126)7.

A atuação construtiva no mundo vem presidida pela habitação. O primeiro e essencial passo consiste em habitar o mundo. Só depois vem a atividade de construir. Trata-se da perspectiva da habitação. Não se pode, porém, circunscrever o acontecimento da habitação humana ao espaço antropocêntrico. Há que pensar o tema de forma mais arejada, envolvendo toda a criação. Talvez seja um dos limites do pensamento heideggeriano, como indica Ingold, na restrição da percepção do modo de habitar o mundo dos animais. Para Heidegger, os animais simplesmente existem no seu ambiente, mas "permanecem privados de um mundo" (INGOLD, 2015, p. 36).

O que domina a visão tradicional, ainda muito vigente, é uma separação rígida entre a vida social humana e a natureza. Com a eco-antropologia relacional rompe-se esta perspectiva e aponta-se para um horizonte distinto, pontuado pela dinâmica da tessitura e do entrelaçamento dos seres humanos com seu ambiente. A humanidade se insere num campo vivo de dignidades peculiares, como a animalidade, a plantidade, a vegetalidade e a mineralidade. Toda a esfera do vivente guarda um valor intrínseco, com seus direitos característicos. No âmbito desta ocular, o diálogo e a hospitalidade ganham uma tessitura nova e abrangente.

\footnotetext{
${ }^{7}$ Num dos preciosos trabalhos do mestre Dôgen, Sansuikyô (Montanhas e rios como sutras), ele assinala que as montanhas e rios traduzem a presença do caminho primordial do despertar. Não captar o movimento das montanhas e rios é desconhecer a Via. Colocar em dúvida a marcha das montanhas é desconhecer os passos da realização de si: DOGEN, 2005, p. 103-104.
} 
A espécie humana se viu enredada numa dinâmica civilizatória mortífera, pautada pela exclusão e pela violência. E como eixo central, a ideia de excepcionalidade:

Nós começamos por nos consideramos especiais em relação aos outros seres vivos. Isso foi o primeiro passo para, em seguida, alguns de nós começar a se achar melhores do que os outros seres humanos. E nisso começou uma história maldita em que você vai cada vez excluindo mais. Você começou por excluir os outros seres vivos da esfera do mundo moral, tornando-os seres em relação aos quais você pode fazer qualquer coisa, porque eles não teriam alma. Esse é o primeiro passo para você achar que alguns seres humanos não eram tão humanos assim. $\mathrm{O}$ excepcionalismo humano é um processo de monopolização do valor. É o excepcionalismo humano, depois o excepcionalismo dos brancos, dos cristãos, dos ocidentais... Você vai excluindo, excluindo, excluindo... até acabar sozinho, se olhando no espelho da sua casa (BRUM, 2014, p. 18-19) ${ }^{8}$.

É o chamado tempo do antropoceno, quando o ser humano deixa de ser um agente biológico para se tornar uma força geológica, alterando radicalmente a paisagem do planeta e comprometendo sua própria existência e sobrevivência. Daí a urgência da superação do antropocentrismo, com todos os seus descaminhos. Uma mudança de rumo é possível, ainda que difícil. Na contramão do itinerário traçado pelos humanos, estão os terranos, os povos de Gaia, com seus sonhos e esperanças. Trata-se, porém, de uma tensão assimétrica, de uma "estranha guerra" cujo destino sombrio está quase definido9.

O questionamento do antropocentrismo implica o redimensionamento do conceito de "nós", não mais restrito à esfera do humano (VIVEIROS DE CASTRO, 2008, p. 257). O ambiente, como aquilo que circunda o organismo, passa a ter uma valência substantiva. Deixa de ser visto como a realidade para a qual olhamos, sendo percebido agora como "um mundo no qual vivemos". Trata-se de uma importante mudança de ocular, que reconfigura a tônica relacional. Um passo

\footnotetext{
${ }^{8}$ Trata-se de uma citação de Eduardo Viveiros de Castro, com base num pensamento de Lévi-Strauss.

${ }^{9} \mathrm{Na}$ visão de Bruno Latour, nessa "guerra" os terranos estão com a causa perdida, dada a força da dinâmica antropocena: LATOUR, Bruno, 2012, p. 483. Os humanos são os modernos, e os terranos, os povos de Gaia: cf. DANOWSKI, D.; VIVEIROS DE CASTRO, E., 2014, p. 122.
} 
importante para acolher o mundo da diversidade e ressignificar os conceitos de diálogo e hospitalidade.

A ampliação de perspectiva requer um novo olhar, ou ainda melhor, uma nova atitude contemplativa sobre o mundo. Em reflexão singular, Octavio Paz fala do processo que acompanha a atitude diante do mundo natural, de um estranhamento inicial a um encantamento peculiar, quando se dá a percepção das malhas de conexão do humano com o seu ambiente:

Diante do mar ou de uma montanha, perdidos entre as árvores de um bosque ou na entrada de um vale que se estende aos nossos pés, nossa primeira sensação é a da estranheza ou separação. Nós nos sentimos diversos. O mundo natural se apresenta como algo alheio, possuidor de uma existência própria. Esse distanciamento se transforma logo em hostilidade. Cada galho de árvore fala uma linguagem que não entendemos; em cada matagal dois olhos nos espiam; criaturas desconhecidas nos ameaçam ou escarnecem de nós. Também pode ocorrer o contrário: a natureza se recolhe em si mesma e o mar se enrola e desenrola à nossa frente, com indiferença; as rochas se tornam ainda mais compactas e impenetráveis; o deserto mais vazio e insondável. Não somos nada diante de tanta existência fechada em si mesma. E desse sentir-nos nada passamos, se a contemplação se prolonga e o pânico não nos embarga, ao estado oposto: o ritmo do mar se adapta ao compasso do nosso sangue; o silêncio das pedras é o nosso próprio silêncio; andar nas areias é caminhar pela extensão da nossa consciência, ilimitada como elas; os sons do bosque nos aludem. Todos nós fazemos parte de tudo (PAZ, 2012, p. 160-161).

Isso é o que os povos originários captam com frequência natural. Uma das importantes lideranças indígenas brasileiras, Ailton Krenak, sublinha que a natureza é algo que existe e brilha em cada uma das células de seu corpo. Todo o entorno vem pontuado pelo toque da fragrância do Mistério. Como ele assinala, o sagrado "pode ser tudo aquilo em que botamos os olhos, a depender dos olhos com que enxergamos o mundo”. Não há por que ver nas montanhas apenas o seu potencial mineralógico ou nos rios o seu capital energético. Há que desvendar a dimensão de Mistério que se esconde por trás de sua aparência superficial (KRENAC, 2015, p. 83 e 231-232). 
Firma-se como essencial no novo século a questão da relação dos humanos com a natureza. Não há como continuar acreditando que a natureza seja um mundo à parte, deslocada da vida social (DESCOLA, 2013, p. 97). Os caminhos que se apresentam são outros, para além do antropocentrismo. O ser humano deixa de ser o "umbigo do mundo" para ser parte do vivente, uma "espécie de companhia”, onde todos os seres da criação passam a ser considerados "parentes”. E não só as coisas visíveis, mas também as invisíveis (FOX, 2016, p. 22).

Abordando especificamente o tema da hospitalidade, com o foco na questão do animal, a pesquisadora Lucille Desblache, reconhece na reflexão uma forma de ampliação da teia da acolhida. Ao alargar os canais de acolhida para criaturas não humanas o que ocorre é uma abertura de horizontes para o entendimento do próprio ser humano, como nó de relações. A abordagem sobre os animais suscita uma nova compreensão dos humanos mesmos. Os animais "nos chamam a partilhar e a nos abrir a outros universos, a outras maneiras de pensar, outras linguagens, outras maneiras diferentes de ser" (MONTANDON, 2011, p. 1249). Thomas Merton, com base em Rilke, chamou a atenção para a simplicidade do animal. Ele está "sempre em contato imediato com a vida”, sem as interposições da consciência. Na sua espontaneidade, simplesmente vive. O seu movimento "é para a eternidade”, sem nostalgia (CARDENAL, 1979, p. 11; RILKE, 2013b, p. 67). Outro aprendizado importante lançado para o ser humano: viver simplesmente.

\section{Habitar espiritualmente a Terra}

A tomada de consciência de que tudo está interligado favorece a retomada do senso da maravilha, que é á única bússula que indica o polo do significado (HESCHEL, 2001, p. 29). Há que se deixar tomar pelo estupor que move a consciência diante da textura do mundo e da dinâmica da vida. A espiritualidade é essa capacidade de celebrar a vida em profundidade. Ela aciona qualidades essenciais e potencialidades de abertura que procedem do espirito. É dela que se irradiam, com uma fragrância única, os toques singulares do amor desinteressado, 
da gratuidade, da atenção, cortesia e hospitalidade. São traços da dinâmica humana quando atuada em profundidade. A espiritualidade aciona o movimento desses valores fundamentais que são irradiados por todo canto. Deixar-se habitar pela espiritualidade é criar o espaço garantido e especial para a emergência de fragrâncias essenciais, que constituem a razão fundamental da existência.

Uma "nova reverência face à vida", eis o desafio que se apresenta a todos nesse século XXI. É a responsabilidade que envolve hoje todos os povos da Terra, em favor de um outro mundo possível. Há que somar forças e unir corações numa comunidade global sintonizada com o cuidado da Terra e a afirmação da dignidade de todos. Como indica a Carta da Terra, "a escolha é nossa: formar uma aliança global para cuidar da Terra e uns dos outros, ou arriscar a nossa destruição e da diversidade da vida” (BOFF, 2002, p. 149).

O papa Francisco na sua encíclica sobre o cuidado da casa comum lançou algumas pistas importantes para essa espiritualidade ecológica. Assumir uma atitude de cuidado da ecologia pressupõe uma atenção ao mundo interior, à paz interior. É desse âmbito interior que procedem os valores essenciais, como a capacidade de admiração e a percepção da profunda interligação que irmana as criaturas. Cada uma delas tem o seu lugar, a sua função e dignidade, não podendo ser descartada como supérflua: "Todo o universo material é uma linguagem do amor de Deus, do seu carinho sem medida por nós. O solo, a água, as montanhas: tudo é carícia de Deus" (FRANCISCO, 2015, p. 68-69).

A harmonia serena com a criação é fruto de um processo peculiar, de trabalho interior, que envolve simples gestos do cotidiano, favorecendo a quebra da lógica de domínio, exclusão ou violência. Da fonte interior secreta a percepção viva de que o Mistério está em toda parte: "há um mistério a contemplar em uma folha, em uma vereda, no orvalho, no rosto do pobre" (FRANCISCO, 2015, p. 184). É uma espiritualidade que retoma uma dimensão nova, receptiva e gratuita, de celebração do mundo da vida. Há uma dimensão espiritual que preside a ligação do ser humano com toda a criação. É um tema muito recorrente na visão da igreja oriental 
antiga. Para os santos dessas comunidades, aqueles que são puros de coração são capazes de perceber nitidamente esses laços. O mundo inteiro, como lembra Massimo o Confessor (580-662), é uma "liturgia cósmica”. A criação como um todo é um "livro sagrado" (BARTHOLOMEUS, 2015, p. 34 e 51). A relação com Terra ganha, assim, uma dimensão mística e sacramental, daí o desafio singular de atenção e escuta ao ritmo do tempo, do silêncio necessário para ouvir o canto das coisas.

Essa nova sensibilidade espiritual vai envolvendo as tradições religiosas, na busca de um "ecumenismo" mais profundo. Como mostrou o monge vietnamita, Thich Nhat Hanh, os seres vivos estão entrelaçados na Terra. Ela não é simplesmente o ambiente em que se vive, mas um componente da trama existencial. Sublinha ainda que um dos motivos que provocam o medo, o ódio ou a raiva relaciona-se com a ideia que desvincula o ser humano da Terra e do planeta, bem como a visão antropocêntrica de que o sujeito é o centro referencial. O olhar despretensioso, purificado, capta uma outra perspectiva: "Quando vemos verdadeiramente que a Terra faz parte de nós, captamos algo de extraordinário. A Terra é viva” (THICH NHAT HANH, 2016, p. 8).

\section{Conclusão}

A reflexão sobre a hospitalidade e o diálogo ganha um significado novo quando inserida nesse leque mais amplo da textura do mundo, da reverência à Terra. Não se trata de uma mera questão inter-subjetiva, que envolve a provocação entre as religiões e espiritualidades. É algo mais radical, que suscita uma percepção de irmandade mais alargada. Dialogar é traçar um novo modo de ser com as espécies companheiras, na abertura incessante ao Mistério maior que se revela a cada momento, nos espaços mais inusitados. Como sublinhou o compositor brasileiro, Gilberto Gil, o “Mistério sempre há de pintar por aí”. Ele está por toda parte a convocar o olhar e a sensibilidade. 
A perspectiva espiritual do habitar a Terra firma-se como decisiva nesse século XXI, apontando para um âmbito novo de vitalidade. Uma sensibilidade nova que pressupõe uma ruptura de paradigma. Não mais dominar e submeter a Terra e os seres da criação, mas instaurar laços de parentesco e irmandade. Cada criatura tem seu valor intrínseco, e nenhuma é supérflua. Na verdade, tudo está intimamente relacionado. As malhas do diálogo e da acolhida ganham, assim, um novo perfil. Na medida em que o ser humano cresce no mundo, é o mundo mesmo que cresce nele (INGOLD, 2015, 30).

Mesmo reconhecendo as dificuldades que acompanham os que defendem um novo paradigma, os povos de Gaia, é preciso reconhecer que a sua luta é essencial para mudar a fisionomia do mundo, ou mesmo garantir a sua sobrevivência. Na manutenção do atual paradigma, defendido pelos humanos no antropoceno, o risco maior é o da autodestruição e devastação da biodiversidade. No novo paradigma, uma sintonia mais fina com os ritmos da natureza e uma dinâmica de cortesia e cuidado com os seres criados, compreendidos como parceiros de uma aliança. O que ocorre é uma grande crise de civilização, onde "há gente de menos com mundo de mais e gente demais com mundos de menos" (DANOWSCK; VIVEIROS DE CASTRO, 2014, p. 129). A grande e decisiva questão que se coloca: em que mundo se quer viver?10

\section{REFERÊNCIAS}

BARTHOLOMEUS I. Nostra madre terra. Magnano: Qiqajon, 2015.

BERGER, Peter L.; LUCKMANN, Thomas. Modernidade, pluralismo e crise de sentido. A orientação do homem moderno. Petrópolis: Vozes, 2004.

BOFF, Leonardo. Do iceberg à arca de Noé. O nascimento de uma ética planetária. Rio de Janeiro: Garamond, 2002.

\footnotetext{
${ }^{10}$ Recorrendo a uma citação de Bruno Latour, Viveiros de Castro sinaliza: "Para falarmos de maneira direta: alguns de nós estão se preparando para viver como Terranos no Antropoceno; outros decidiram permanecer como Humanos no Holoceno": DANOWSKI; VIVEIROS DE CASTRO, 2014, p. 123.
} 
BRUM, Eliane. Diálogos sobre o fim do mundo. El país, 29/09/2014. Disponível em: <http://brasil.elpais.com/brasil/2014/o9/29/opinion/1412000283_365191.html>. Acesso realizado em: $03 / 02 / 2017$.

CARDENAL, Ernesto. Vida no amor. Rio de Janeiro: Civilização Brasileira, 1979.

DANOWSKI, Débora; VIVEIROS DE CASTRO, Eduardo. Há mundo por vir? Ensaio sobre os medos e os fins. Florianópolis/São Paulo: Cultura e Barbárie/Instituto Socioambiental, 2014.

DESCOLA, Philippe. L'ecologia degli altri. L'antropologia e la questione della natura. Roma: Linaria, 2013.

DÔGEN, Maître. Shôbôgenzô. La vrai Loi, Trésor de l’ Oeil. Tome 1. Paris: Sully, 2005.

DUQUOC, Christian. O único Cristo. A sinfonia adiada. São Paulo: Paulinas, 2008.

FORTE, Bruno. Teologia in dialogo. Milano: Raffaello Cortina, 1999.

FOX, Matthew. La spiritualità del creato. Manuale di mistica ribelle. San Pietro in Cariano: Gabrielli, 2016.

GADAMER, Hans-Georg. Verdade e Método II. Petrópolis: Vozes, 2002.

GEFFRÉ, Claude. A crise da identidade cristã na era do pluralismo religioso. Concilium, Petro polis, v. 311, n. 3, 2005.

GEFFRÉ, Claude. De Babel à Pentecôte. Essais de théologie interreligieuse. Paris: Cerf, 2006.

HAROUCHE-BOUZINAC, Geneviève. "Supondo que seja necessário ligar a amizade à hospitalidade”. In: MONTANDON, Alan. O livro da hospitalidade: Acolhida do estrangeiro na história e nas culturas. São Paulo: Senac, 2011.

HART, Patrick; MONTALDO, Jonathan (Eds). Merton na intimidade. Sua vida em seus diários. Rio de Janeiro: Fisus, 2001.

HEIDEGGER, Martin. Que é metafísica ?. São Paulo: Duas Cidades, 1969.

HESCHEL, Abraham Joshua. L’uomo non è solo. Milano: Mondadori, 2001.

HOMERO. Odisseia. São Paulo: Companhia das Letras, 2011.

INGOLD, TIM. Estar vivo. Ensaios sobre movimento, conhecimento e descrição. Petrópolis: Vozes, 2015.

KOPENAWA, Davi; ALBERT, Bruce. A queda do céu. Palavras de um xamã yanomami. São Paulo: Companhia das Letras, 2015.

KRENAK, Ailton. Encontros. Rio de Janeiro: Azougue, 2015. 
KÜNG, Hans. Projeto de ética mundial. Uma moral ecumênica em vista da sobrevivência humana. São Paulo: Paulinas, 1992.

LATOUR, Bruno. Enquête sur les modes d'existence. Une anthropologie des modernes. Paris: La Découverte, 2012.

LUCCHESI, Marco. Guerras de religião. O GLOBO, 03/12/2014. Disponível em: <http://noblat.oglobo.globo.com/geral/noticia/2014/12/guerras-de-religiao.html>.

Acesso realizado em: 04/02/2017.

LUCCHESI, Marco. Os olhos do deserto. Rio/São Paulo: Record, 2000.

MONTANDON, Alain (Ed). O livro da hospitalidade. Acolhida do estrangeiro na história e nas culturas. São Paulo: Senac, 2011.

MONTANDON, Alain. A difícil e necessária dádiva da reciprocidade. IHU-Online, São Leopoldo, v. 16, n. 499, 19/12/2016.

PANIKKAR, Raimon. Dialogo interculturale e interreligioso. Culture e religioni in dialogo tomo 2. Milano: Jaca Book, 2013.

PANIKKAR, Raimon. Religion (Dialogo intrarreligioso). In: FLORISTAN, Casiano; TAMAYO, Juan José (Eds). Conceptos fundamentales del cristianismo. Madrid: Trotta, 1993.

PAPA FRANCISCO. "O perigo em tempos de crise é buscar um salvador que nos devolva a identidade e nos defenda com muros". El País, 22/01/2017. Disponível em: <http://brasil.elpais.com/brasil/2017/o1/21/internacional/1485022162_846725.html>. Acesso realizado em: 04/02/2017.

PAPA FRANCISCO. Evangelii Gaudium. A alegria do evangelho. São Paulo: Paulus/Loyola, 2013b.

PAPA FRANCISCO. Laudato si. Sobre o cuidado da casa comum. São Paulo: Paulinas, 2015 .

PAPA FRANCISCO. Palavras do Papa Francisco no Brasil. São Paulo: Paulinas, 2013.

PAZ, Octavio. O arco e a lira. São Paulo: Cosac Naify, 2012.

PONTIFÍCIO Conselho para o Diálogo Inter-Religioso. Diálogo e anúncio. Petrópolis: Vozes, 1991 (PCDI).

RILKE, Rainer Maria. Cartas a um jovem poeta. 4 ed. São Paulo: Globo, 2013a.

RILKE, Rainer Maria. Elegias de Duíno. 6 ed. São Paulo: Globo, 2013 b.

SAID, Edward W. Cultura e política. São Paulo: Boitempo, 2003a.

SAID, Edward. Reflexões sobre o exílio e outros ensaios. São Paulo: Companhia das Letras, 2003b. 
SEVENAER, Christian Van Nispen Tot. Cristiani e musulmani: fratelli davanti a Dio? Venezia: Marcianum Press, 2006.

TEIXEIRA, Faustino. Cristianismo e diálogo inter-religioso. São Paulo: Fonte Editorial, 2014.

TICH NHAT HANH. Lettera d’amore alla madre terra. Milano: Garzanti, 2016.

TILLARD, Jean-Marie Roger. Dialogare per non morire. Bologna: EDB, 2000.

TILLICH, Paul. Le christianisme et les religions. Paris: Aubier, 1968.

VIVEIROS DE CASTRO, Eduardo. Encontros. Rio de Janeiro: Azougue, 2008.

WEIL, Simone. A la espera de Dios. 3 ed. Madrid: Trotta, 2000.

WEIL, Simone. Carta a um religioso. Petrópolis: Vozes, 2016.

WEIL, Simone; BOUSQUET, Joë. Corrispondenza. Milano: SE SRL, 1994. 